\title{
Microarray data analysis reveals gene expression changes in response to ionizing radiation in MCF7 human breast cancer cells
}

\author{
Jing Bai ${ }^{1}$, Youzhen Luo ${ }^{1}$ and Shengchu Zhang ${ }^{2^{*}}$
}

\begin{abstract}
Background: The aim of this study was to identify potential therapeutic target genes for breast cancer (BC) by the investigation of gene expression changes after ionizing radiation (IR) in BC cells. Gene expression profile GSE21748, including BC cell line MCF-7 samples at different time points after IR treatment, were downloaded from Gene Expression Omnibus. Differentially expressed genes (DEGs) were identified in different time points following IR compared with cell samples before IR, respectively. Gene ontology functions and The Kyoto Encyclopedia of Genes and Genomes pathways of the overlapping DEGs were enriched using DAVID. Transcription factor (TFs)-encoding genes were identified from the overlapping DEGs, followed by construction of transcriptional regulatory network and co-expression network.
\end{abstract}

Results: A total of 864 overlapping DEGs were identified, which were significantly enriched in regulation of cell proliferation and apoptosis, and cell cycle process. We found that FOXD1, STAT6, XBP1, STAT2, LMO2, TFAP4, STAT3, STAT1 were hub nodes in the transcriptional regulatory network of the overlapping DEGs. The co-expression network of target genes regulated by STAT3, STAT1, STAT6 and STAT2 included some key genes such as BCL2L1.

Conclusion: STAT1, STAT2, STAT3, STAT6, XBP1, BCL2L1, CYBSD2, ESCO2, and PARP2 were significantly affected by IR and they may be used as therapeutic gene targets in the treatment of BC.

Keywords: Breast cancer, Differentially expressed gene, Gene expression omnibus, Therapeutic gene targets, Transcriptional regulatory network

\section{Background}

Breast cancer $(\mathrm{BC})$, one of the most common cancers among women, accounts for about $25 \%$ of all kinds of cancers $[1,2]$. Mammary gland is not an important organ to maintain human life activities and $\mathrm{BC}$ in situ is not fatal. However, due to the loss of the characteristics of normal cells, the cells are loosely connected and easy to fall off. Once detached, free cancer cells can spread throughout the body by the blood or

\footnotetext{
* Correspondence: m2sum4u996@sina.com

2Department of Thyroid and Breast Surgery, The First College of Clinical Medical Sciences, China Three Gorges University, Yichang Central People's Hospital, No. 183 Yiling Road, Wujia District, Yichang 443000, Hubei, China Full list of author information is available at the end of the article
}

lymph, forming metastases that threaten life [3]. Despite great improvements in screening, diagnosis and treatment strategies, the prognosis and survival outcomes for breast cancer patients remain unsatisfactory [4].

In recent year, high-dosage ionizing radiation (IR) is considered to be an effective treatment for BC. Radiotherapy can significantly reduce local recurrence, $\mathrm{BC}$ specific mortality and total mortality $[5,6]$. IR is radiation that carries enough energy to make the electrons in atoms or molecules of a material into a free state, thus ionizing those atoms or molecules [7]. In briefly, the idea behind IR therapy is that rapidly proliferating cancer cells are more sensitive to 
radiation than normal cells, which can repair themselves more quickly and maintain their normal function $[8,9]$. So the goal of IR therapy is to inhibit the proliferative potential of cancer cells and lead to cell death, while reducing IR uptake by normal cells [10].

The response of cells to IR is a dynamic process from growth stagnation to apoptosis. And IR-induced cellular effects include sister chromatid exchange, pigment distortion, apoptosis, micronucleation, transformation, mutation and gene expression alteration [11]. In briefly, cancer cell apoptosis is achieved by DNA strand damage or indirect production of free radicals after received high-dosage IR, while the production of free radicals can indirectly damage DNA [12]. This damage is called repair-resistant or non-repairable [6]. The DNA damage response is generally activated when cells respond to these challenges. And the process of DNA damage response includes coordinating the transmission of DNA damage signals, triggering DNA repair and cell survival or apoptosis [13]. The cell response to IR is mediated by genes that control and regulate complex regulatory pathways [14]. Detection of changes in gene expression is an effective method to understand the mechanism of the above reaction. The research on transcriptional gene regulation of IR is mainly to understand how the human body reacts to IR and how radiation hazards develop.
In the present study, microarray data of gene expression in BC cells at different time points after IR were downloaded from Gene Expression Omnibus (GEO) database, and further differentially expressed genes (DEGs) were screened. Gene Ontology (GO) and The Kyoto Encyclopedia of Genes and Genomes (KEGG) pathways of the overlapping DEGs were analyzed. Then key transcription factor (TFs)-encoding genes were screened from the overlapping DEGs, followed by construction of transcriptional regulatory network and coexpression network, with the aim to identify potential therapeutic target genes for $\mathrm{BC}$.

\section{Results}

\section{Overlapping DEGs analysis}

To determine the DEGs after IR treatment in breast cancer, a microarray dataset GSE2178, obtained from MCF7 human breast cancer cells, was downloaded from GEO. We obtained expression information of 18,179 genes from 20 samples. Box plots showed the median of expression value approximated a straight line, indicating good normalization (Fig. 1a). Totally, 1250 DEGs (592 down-regulated genes and 658 up-regulated genes) were identified after IR at day 1, 3405 DEGs at day 2 (1770 down-regulated genes and 1635 up-regulated genes), 3597 DEGs at day 3 (1773 down-regulated genes and 1824 up-regulated genes), and 6746 DEGs at day 4 (3477

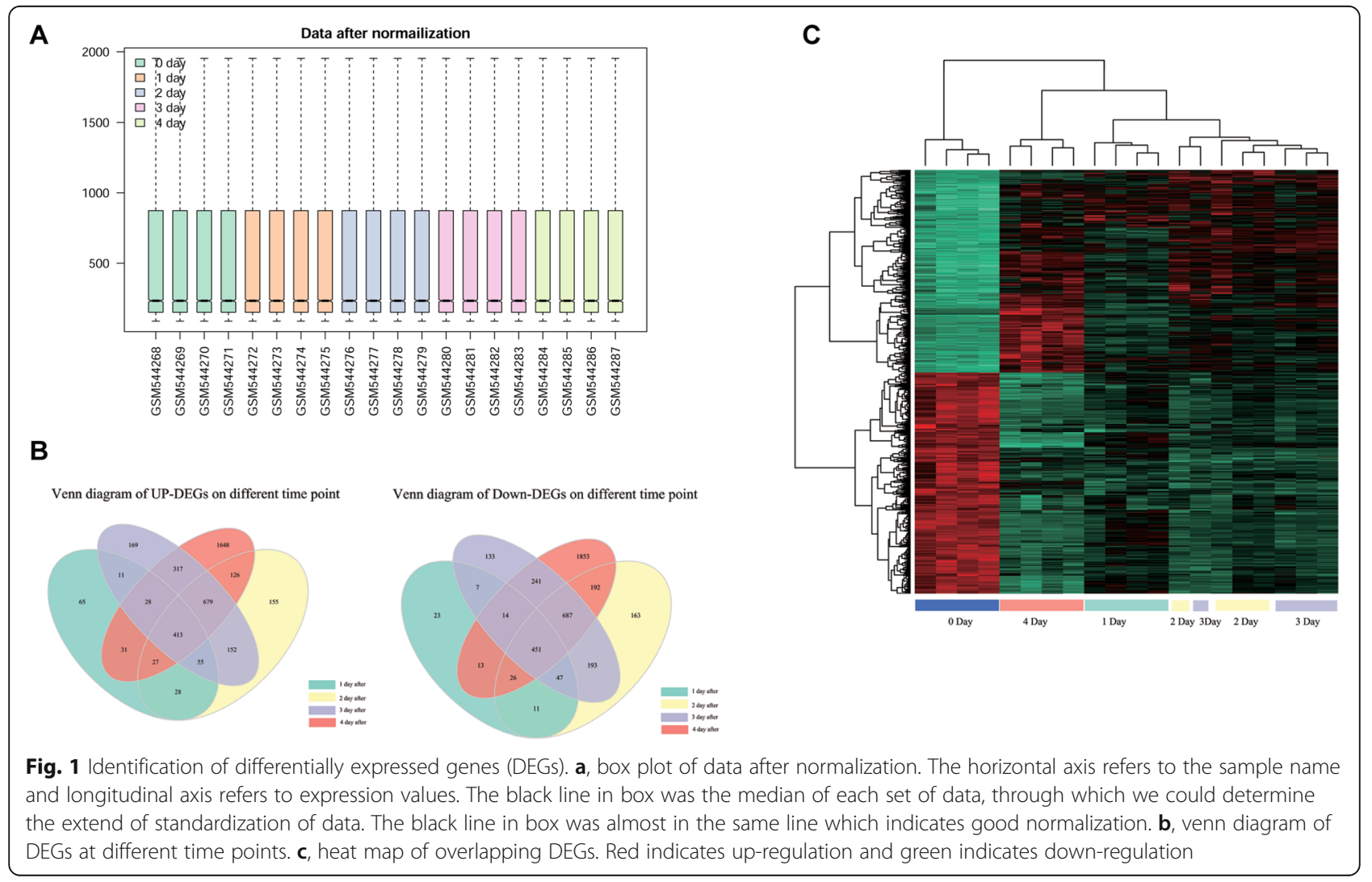


down-regulated genes and 3269 up-regulated genes) compared with the control group, respectively (Table 1). Venn diagram of Up-DEGs indicated that 413 overlapping DEGs were up-regulated at four different time points (Fig. 1b). Venn diagram of Down-DEGs indicated that 451 overlapping DEGs were down-regulated at four different time points (Fig. 1b).

From the heat map of the overlapping DEGs (Fig. 1c), we found that there was difference in DEGs expression patterns between the IR-group and control-group. The four samples on the first day post-IR or on the fourth day after radiotherapy were clustered into one category, respectively. The differences between the eight samples on days 2 and 3 were not significant. It was obviously observed that the expression of genes originally up-regulated in breast cancer began to be down-regulated after radiotherapy. It can be clearly seen from the depth of green in the Fig. 1c that the degree of down-regulation gradually deepened from the first day of the fourth day after radiotherapy. The expression level of genes originally down-regulated in breast cancer was up-regulated after radiotherapy, and the upregulated level was significantly increased over time.

\section{GO and pathway enrichment analysis}

In order to analyze the function of DEG and the involved pathways, DAVID was used to observe significant enrichment of these genes in multiple KEGG and GO terms. Results showed that the overlapping up-regulated DEGs were enriched in biological processes such as cell proliferation, energy metabolism and apoptosis process (Table 2); overlapping down-regulated DEGs were enriched in biological processes as cell mitosis and DNA damage repair (Table 3). Moreover, the overlapping upregulated genes were associated with the pathways such as p53 signaling pathway, lysosome, and glutathione metabolism; the overlapping down-regulated genes were associated with the pathways such as DNA replication, cell cycle, and pyrimidine metabolism.

\section{Construction of transcriptional regulatory network}

A total of 12 genes that encoded TFs were found in the overlapping up-regulated DEGs, and 24 genes that encoded TFs were identified in the overlapping downregulated DEGs. According to the transcriptional regulatory network which was arranged in a radial pattern, we

Table 1 Differentially expressed genes at different time points

\begin{tabular}{llll}
\hline \multirow{2}{*}{$\begin{array}{l}\text { Time } \\
\text { (Day) }\end{array}$} & \multicolumn{2}{l}{ Number of significantly regulated genes } \\
\cline { 2 - 4 } & Down-regulated genes & Up-regulated genes & Total \\
\hline 1 Day & 592 & 658 & 1250 \\
2 Day & 1770 & 1635 & 3405 \\
3 Day & 1773 & 1824 & 3597 \\
4 Day & 3477 & 3269 & 6746 \\
\hline
\end{tabular}

found that 8 of the 36 TF encoding genes regulated more target genes, including Forkhead Box D1 (FOXD1, down-regulated, degree of connectivity $=444$ ), Signal Transducer And Activator Of Transcription 6 (STAT6, down-regulated, degree of connectivity $=587$ ), X-Box Binding Protein 1 (XBP1, down-regulated, degree of connectivity $=806$ ), STAT2 (down-regulated, degree of connectivity $=948)$, LIM Domain Only $2($ LMO2, downregulated, degree of connectivity $=1130$ ), Transcription Factor AP-4 (TFAP4, down-regulated, degree of connectivity $=1584)$, STAT3 (down-regulated, degree of connectivity $=1635$ ), and STAT1 (Signal Transducer And Activator Of Transcription 1, down-regulated, degree of connectivity $=1968$ ) (Fig. 2). Then we screened the target genes in the overlapping DEGs regulated by STAT1, STAT3, STAT2 and STAT6, and 14 genes were obtained, which were then subjected to the coexpression network construction (Fig. 3). Genes in the co-expression network included BCL2 Like 1 (BCL2L1), Cytochrome B5 Domain Containing 2 (CYB5D2), Tetraspanin 31 (TSPAN31), Galactosidase Alpha (GLA), ATP Synthase Peripheral Stalk Subunit OSCP (ATP5O), SET Nuclear Proto-Oncogene (SET), Centrosomal Protein 55 (CEP55), Vaccinia Related Kinase 1 (VRK1), Establishment Of Sister Chromatid Cohesion N-Acetyltransferase 2 (ESCO2), Poly (ADP-Ribose) Polymerase 2 (PARP2) and Pre-MRNA Processing Factor 4 (PRPF4).

\section{Discussion}

In this study, bioinformatics approach was used to predict potential therapeutic targets for $\mathrm{BC}$. We have identified 864 overlapping DEGs between IR groups and control group, among which 413 genes were down-regulated and 451 ones were up-regulated. By constructing transcriptional regulatory network, we found several key hub nodes including STAT3, STAT6, XBP1, STAT2 and STAT1. Moreover, co-expression network on the genes regulated by STAT3, STAT6, STAT2 and STAT1 was constructed.

Studies showed that target genes regulated by STAT proteins were important in cancers [15-17]. STAT family proteins regulate the expression of a variety of genes involved in cell growth, survival, differentiation and apoptosis $[18,19]$. A total of seven STAT proteins have been identified, including STAT1 2, 3, 4, 5a, 5b, and $6[18,19]$. Studies have shown that some members of the STAT family are tumor suppressor genes of $\mathrm{BC}$, while others are oncogenes [20, 21]. Kolla et al. found that STAT1 was tumor suppressors and lack of their expression may be involved in tumorigenesis [22]. Jung et al. showed that STAT1 are downstream targets in MCF-7 human BC cell and have tumor suppressor function in $\mathrm{BC}$ [23]. Gooch et al. found that STAT6 mediates the inhibition of interleukin-4 growth in human BC cells [24]. Studies found that STAT3 was an oncogene and over expressed in BC [25]. Behera 
Table 2 GO and KEGG enrichment results of the up-regulated genes

\begin{tabular}{|c|c|c|c|}
\hline Category & Term & Count & $\boldsymbol{P}$ Value \\
\hline GOTERM_BP_FAT & GO:0042127 regulation of cell proliferation & 30 & 0.001054887 \\
\hline GOTERM_BP_FAT & GO:0042981 regulation of apoptosis & 29 & 0.002919188 \\
\hline GOTERM_BP_FAT & GO:0043067 regulation of programmed cell death & 29 & 0.003382978 \\
\hline GOTERM_BP_FAT & GO:0010941 regulation of cell death & 29 & 0.003532924 \\
\hline GOTERM_BP_FAT & GO:0008104 protein localization & 26 & 0.048175685 \\
\hline GOTERM_CC_FAT & GO:0005739 mitochondrion & 37 & 0.001607912 \\
\hline GOTERM_CC_FAT & GO:0005829 cytosol & 37 & 0.033925941 \\
\hline GOTERM_CC_FAT & GO:0031090 organelle membrane & 35 & 0.006084384 \\
\hline GOTERM_CC_FAT & GO:0005794 Golgi apparatus & 30 & 0.004372382 \\
\hline GOTERM_CC_FAT & GO:0005626 insoluble fraction & 26 & 0.027666166 \\
\hline GOTERM_MF_FAT & GO:0046983 protein dimerization activity & 21 & 0.003932064 \\
\hline GOTERM_MF_FAT & GO:0042802 identical protein binding & 23 & 0.005855689 \\
\hline GOTERM_MF_FAT & GO:0043028 caspase regulator activity & 4 & 0.017632928 \\
\hline GOTERM_MF_FAT & GO:0048037 cofactor binding & 11 & 0.021981803 \\
\hline GOTERM_MF_FAT & GO:0042803 protein homo dimerization activity & 13 & 0.027801507 \\
\hline KEGG_PATHWAY & hsa04115:p53 signaling pathway & 8 & 0.001608728 \\
\hline KEGG_PATHWAY & hsa04142:Lysosome & 10 & 0.002837651 \\
\hline KEGG_PATHWAY & hsa05416:Viral myocarditis & 7 & 0.009152891 \\
\hline KEGG_PATHWAY & hsa00480:Glutathione metabolism & 5 & 0.037989004 \\
\hline
\end{tabular}

Table $3 \mathrm{GO}$ and KEGG enrichment results of the down-regulated genes

\begin{tabular}{|c|c|c|c|}
\hline Category & Term & Count & $\boldsymbol{P}$ Value \\
\hline GOTERM_BP_FAT & GO:0007049 cell cycle & 99 & $3.71 \mathrm{E}-44$ \\
\hline GOTERM_BP_FAT & GO:0006259 DNA metabolic process & 80 & $6.51 \mathrm{E}-42$ \\
\hline GOTERM_BP_FAT & GO:0022402 cell cycle process & 76 & 9.75E-35 \\
\hline GOTERM_BP_FAT & GO:0022403 cell cycle phase & 69 & 2.49E-37 \\
\hline GOTERM_BP_FAT & GO:0000279 M phase & 63 & $1.32 \mathrm{E}-37$ \\
\hline GOTERM_CC_FAT & GO:0043232 intracellular non-membrane-bounded organelle & 125 & 2.16E-21 \\
\hline GOTERM_CC_FAT & GO:0043228 non-membrane-bounded organelle & 125 & 2.16E-21 \\
\hline GOTERM_CC_FAT & GO:0070013 intracellular organelle lumen & 106 & 1.53E-24 \\
\hline GOTERM_CC_FAT & GO:0043233 organelle lumen & 106 & $9.59 \mathrm{E}-24$ \\
\hline GOTERM_CC_FAT & GO:0031974 membrane-enclosed lumen & 106 & $4.56 \mathrm{E}-23$ \\
\hline GOTERM_MF_FAT & GO:0003677 DNA binding & 92 & $1.81 \mathrm{E}-08$ \\
\hline GOTERM_MF_FAT & GO:0000166 nucleotide binding & 91 & $6.03 \mathrm{E}-09$ \\
\hline GOTERM_MF_FAT & GO:0017076 purine nucleotide binding & 83 & 1.95E-09 \\
\hline GOTERM_MF_FAT & GO:0032555 purine ribonucleotide binding & 82 & $5.64 \mathrm{E}-10$ \\
\hline GOTERM_MF_FAT & GO:0032553 ribonucleotide binding & 82 & $5.64 \mathrm{E}-10$ \\
\hline KEGG_PATHWAY & hsa03030:DNA replication & 22 & $1.63 \mathrm{E}-25$ \\
\hline KEGG_PATHWAY & hsa04110:Cell cycle & 26 & $1.22 \mathrm{E}-16$ \\
\hline KEGG_PATHWAY & hsa00240:Pyrimidine metabolism & 13 & $3.29 \mathrm{E}-06$ \\
\hline KEGG_PATHWAY & hsa03430:Mismatch repair & 12 & $1.60 \mathrm{E}-12$ \\
\hline
\end{tabular}




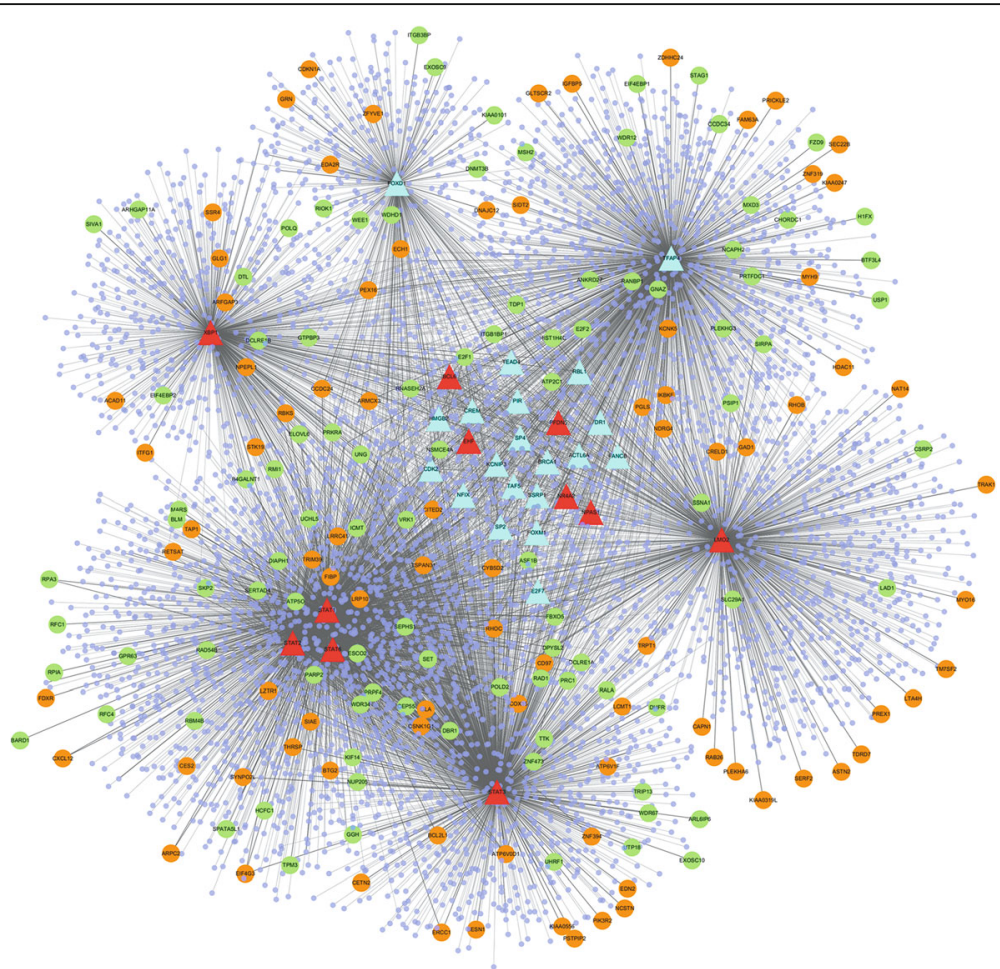

Fig. 2 Transcriptional regulatory network of transcription factors (TFs) and target genes. Triangle nodes refer to corresponding genes of TFs, dots to the target genes regulated by TFs, purple dots that do not give name of genes were differentially expressed genes which were not focused on in this study, the green dots to down-regulated genes, orange dots to up-regulated genes, the red triangles to up-regulated TFs coding genes, blue triangles to down-regulated TFs coding genes

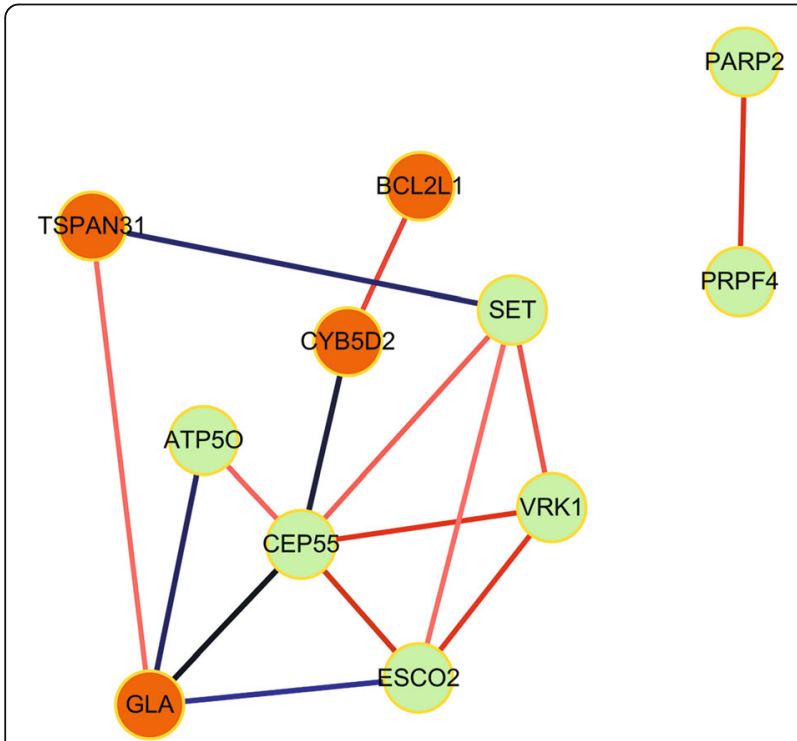

Fig. 3 Co-expression network of DEGs regulated by STAT1, STAT2, STAT3 and STAT6. Edge refers to absolute value of similarity coefficient of the expression of two genes in different samples was greater than 0.85 and $p$ value $<0.05$, the red edge represented the positive correlation, green edge represented negative correlation, orange node represented up-regulated genes, green nodes for down-regulated genes et al found that osteopontin can promote tumor growth of human BC cells by activating the JAK2/STAT3 signaling pathway [26]. Bharadwaj et al. found that many biological processes were regulated by STAT3, including cancer cell growth, apoptosis resistance, and DNA damage response. Moreover, STAT3 has also been proved to be the target of tumor therapy [27]. Wei et al. showed that STAT6 was required for the inhibition of BC cell growth [28]. In our study, according to the result of GO and pathway analysis, we found that STAT1 STAT2, STAT3, and STAT6 may be involved in the biological processes like cell proliferation, apoptosis and programmed cell death. Therefore, we speculated that STAT1 STAT2, STAT3 and STAT6 could be therapeutic targets for BC.

Among the key hub nodes there was also XBP-1, one kind of basic region leucine zipper protein, which has reported having a high expression level Estrogen receptor alpha (ER $\alpha$ )-positive breast tumors [29-32]. ER $\alpha$ has been a primary target of treatment as well as a prognostic indicator for $\mathrm{BC}$ [33]. Studies have found that the transcription level of XBP-1 is related to ER $\alpha$ and can increase the transcriptional activity of ER $\alpha$. This process is achieved by regulating the chromatin unfolding in $\mathrm{BC}$ [33, 34]. Furthermore, some studies showed that activation of ER $\alpha$ is responsible for many biological processes, 
including cell growth and differentiation and programmed cell death $[32,35]$. Overexpression of XBP1 has been identified in primary BC [36] while XBP-1 was down-regulated after radiotherapy treatment. Thus, we suggested that XBP-1 may be a key regulator underlying the development of $\mathrm{BC}$.

Among the genes significantly affected by ionizing radiation, we discovered $\mathrm{BCL} 2 \mathrm{~L} 1$, a gene involved in the regulation of apoptosis [37], and CYB5D2 that inhibits cell proliferation and has a putative tumor suppressor activity [38]. Anthony et al. suggested that CYB5D2 was an inhibitor of cell proliferation and had putative tumor suppressor activity [39]. BCL2L1 and CYB5D2 were all in the CpG island, indicating lower expression of them may be caused by the methylation that leading to gene silencing. DNA methylation, which primarily occurs at $\mathrm{CpG}$ sites plays an important role in transcriptional regulation and tumor initiation [40, 41]. Overall, BCL2L1 and CYBSD2 could be attractive targets for future $\mathrm{BC}$ therapies.

VRK1, ESCO2, and PARP2 were included in the co-expression network (Fig. 3). Thereinto, VRK1 as proliferation-promoting nuclear kinase has been reported to play a role in cell migration and invasion. Overexpression of VRK1 can promote a mesenchymal to epithelial transition (MET) in cell culture, while VRK1mediated MET might facilitate the colonization of distal sites by metastatic BC cells [42]. Additionally, the effect of VRK1 to protect against DNA damage was determined by studying the effect of its knockdown on the formation of DNA repair in response to treatment with IR in BC cell line [43]. ESCO2 has been described as a regulator of mitosis and required for DNA damage repair $[44,45]$. As a mitosis regulator, ESCO2 could uniquely promote cohesion between sister chromatids [46]. GO analysis showed that PARP2 and ESCO2 mainly involved in the metabolic process of DNA and could respond to DNA damage repair. All the results suggested that VRK1, ESCO2 and PARP2 might participate in the process of resistant $\mathrm{BC}$ and could be used as new drug targets since these genes may contribute to cell protection against DNA damage.

\section{Conclusions}

In conclusion, the STAT1, STAT2, STAT3, STAT6, $X B P 1, B C L 2 L 1, C Y B 5 D 2$, ESCO2, and PARP2 may be an important component in the progression and development of $\mathrm{BC}$. As potential specific targets for the treatment of BC, they may play an important role. Meanwhile, necessary clinical validation trials are also a key part of verifying the accuracy of these potential therapeutic targets.

\section{Methods}

\section{Affymetrix microarray data}

Based on the platform of GPL6104 (Illumina humanRef8 v2.0 expression beadchip) which was deposited in GEO (http://www.ncbi.nlm.nih.gov/geo/), the expression profile GSE21748 was obtained [47]. MCF-7 samples in this study were exposed to $\gamma$-ray with a ${ }^{137} \mathrm{Cs} \gamma$-ray source at a dose rate of $3.0 \mathrm{~Gy} / \mathrm{min}$. Samples which were treated with IR after 1 day, 2 day, 3 day, 4 day and no treatment ( 0 day) were collected. Each time point included 4 repeat samples. We also downloaded the raw data and annotation files from GEO database.

Probes with missing expression values were removed, the probe name was converted to gene name using the platform annotation information, and the average expression values of different probes that corresponded to the same gene were considered as the expression value of this gene. In addition, the data were normalized using the median method and the data distribution was displayed using box plots. Then, the DEGs between IRgroup and control-group (day0) were analyzed by limma package in $\mathrm{R}$ [48]. Using Beniamini-Hochberg false discovery rate (FDR), the multiple testing correction was performed [49]. The DEGs with adjusted $p$-value $<0.05$ and $\mid \log$ fold change $(\mathrm{FC}) \mid>2$ were considered to be significant.

\section{Overlapping DEGs analysis}

Venn diagrams of up-DEGs and down-DEGs at different time points were performed, respectively. The common DEGs were selected. Based on the probe information in the download file, the expression value of each group's overlapping data was selected. Based on the Euclidean distance, the $\mathrm{R}$ language pheatmap package (http://cran. r-project.org/web/packages/pheatmap/index.html) was used for Hierarchical clustering [50] of the overlapping DEGs [51]. The heat map was used as the result display. Using Duplexing cluster, genes having similar expression levels were collected together for a further research.

\section{Gene ontology (GO) and pathway enrichment analysis}

In this study, GO function and Kyoto Encyclopedia of Genes and Genomes (KEGG) pathway of the overlapping DEGs were analyzed using The Database for Annotation, Visualization and Integrated Discovery (DAVID, version 6.8, https://david.ncifcrf.gov/) with the threshold of $p$-value $<0.05$.

\section{Transcriptional regulatory network analysis}

The genes encoding TFs were screened from the collection of the overlapping DEGs based on the information provided by Transcription Factor Database (TRANSFAC ) [52]. The interactions between target genes and transcription factors (TFs) were predicted using TF binding sites information from the UCSC database [53]. Using 
Cytoscape, the transcriptional regulatory network was constructed [54]. The calculation of the connectivity of TF nodes, the selection of key TF and key target genes was carried out by using Igraph package. In addition, functional analysis of key genes was performed in combination with expression trend information. Then, we selected target genes regulated by significant TFs from the overlapping DEGs, and calculated the correlation coefficient between them. The co-expression gene pairs with Pearson similarity coefficient $>0.85$ and $p$-value $<0.05$ were selected and used to build the co-expression network.

\section{Acknowledgements}

None.

\section{Authors' contributions}

Conception and design of the research: JB, SZ; acquisition of data: JB, YL; analysis and interpretation of data: $Y L, J B$; statistical analysis: JB, $Y L$; drafting the manuscript: JB; revision of manuscript for important intellectual content: SZ. All authors read and approved the final manuscript.

\section{Funding}

None.

\section{Availability of data and materials}

The datasets used and/or analyzed during the current study are available from the corresponding author on reasonable request.

\section{Ethics approval and consent to participate}

Not applicable.

\section{Consent for publication}

Not applicable.

\section{Competing interests}

The authors declare that they have no competing interests.

\section{Author details}

${ }^{1}$ Department of Gynaecology, The First College of Clinical Medical Sciences, China Three Gorges University, Yichang Central People's Hospital, Yichang 443000, Hubei, China. ${ }^{2}$ Department of Thyroid and Breast Surgery, The First College of Clinical Medical Sciences, China Three Gorges University, Yichang Central People's Hospital, No. 183 Yiling Road, Wujia District, Yichang 443000, Hubei, China.

Received: 13 January 2020 Accepted: 26 August 2020

Published online: 03 September 2020

\section{References}

1. Ginsburg O, Bray F, Coleman MP, Vanderpuye V, Eniu A, Kotha SR, et al. The global burden of women's cancers: a grand challenge in global health. Lancet. 2017;389(10071):847-60.

2. Allahverdiyev A, Tari G, Bagirova M, Abamor ES. Current approaches in development of immunotherapeutic vaccines for breast Cancer. J Breast Cancer. 2018:21(4):343-53.

3. Muller A, Homey B, Soto H, Ge N, Catron D, Buchanan ME, et al. Involvement of chemokine receptors in breast cancer metastasis. Nature. 2001;410(6824):50-6.

4. Mincey BA, Perez EA. Advances in screening, diagnosis, and treatment of breast Cancer. Mayo Clin Proc. 2004;79(6):810-6.

5. Blichert-Toft M, Nielsen M, Düring M, Møller S, Rank F, Overgaard M, et al. Long-term results of breast conserving surgery vs. mastectomy for early stage invasive breast cancer: 20-year follow-up of the Danish randomized DBCG-82TM protocol. Acta Oncol. 2008:47(4):672-81.

6. Clarke RC, Darby S, Davies C, Elphinstone P, Evans V, Godwin J, Gray R, Hicks C, James S, Mackinnon E, McGale P, McHugh T, Peto R, Taylor C, Wang Y. Effects of radiotherapy and of differences in the extent of surgery for early breast cancer on local recurrence and 15-year survival: an overview of the randomised trials. Lancet. 2006;366(9503):0-2106.

7. Lyashchenko K, Vasileva D, Andreev OY, Voitkiv A. QED theory of elastic electron scattering on hydrogen-like ions involving formation and decay of autoionizing states. Physical Review Research. 2020;2(1):013087.

8. Baskar R, Dai J, Wenlong N, Yeo R, Yeoh K. Biological response of cancer cells to radiation treatment. Front Mol Biosci. 2014;1:24.

9. Mehta SR, Suhag V, Semwal M, Sharma N. Radiotherapy: Basic concepts and recent advances. Med JArmed Forces India. 2010;66:158-62.

10. Bernier J, Hall EJ, Giaccia A. Radiation oncology: a century of achievements. Nat Rev Cancer. 2004:4(9):737-47.

11. Chaudhry MA. Analysis of gene expression in Normal and Cancer cells exposed to $\gamma$-radiation. J Biomed Biotechnol. 2008:2008(1):541678.

12. Georgakilas AG. Bystander and non-targeted effects: a unifying model from ionizing radiation to cancer. Cancer Lett. 2015;356(1):3-4.

13. Zacharenia N, Athanasia P, Marcela H, Mattia D, loannis M, Alma B, et al. Bridging plant and human radiation response and DNA repair through an in Silico approach. Cancers. 2017;9(65):1-20

14. Ding LH, Shingyoji M, Chen F, Hwang JJ, Burma S, Lee C, et al. Gene expression profiles of normal human fibroblasts after exposure to ionizing radiation: a comparative study of low and high doses. Radiat Res. 2005; 164(1):17-26.

15. He B, You L, Uematsu K, Zang K, Xu Z, Lee AY, et al. SOCS-3 is frequently silenced by hypermethylation and suppresses cell growth in human lung cancer. Proc Natl Acad Sci U S A. 2003;100(24):14133-8.

16. Nakagawa $T$, lida $S$, Osanai T, Uetake H, Aruga T, Toriya $Y$, et al. Decreased expression of SOCS-3 mRNA in breast cancer with lymph node metastasis. Oncol Rep. 2008;19(1):33-9.

17. Shi Y, Fan X, Meng W, Deng H, Zhang N, An Z. Engagement of immune effector cells by trastuzumab induces HER2/ERBB2 downregulation in cancer cells through STAT1 activation. Breast Cancer Res. 2014;16(2):R33.

18. Levy DE, Darnell JE Jr. Stats: transcriptional control and biological impact. Nat Rev Mol Cell Biol. 2002;3(9):651-62.

19. Yu H, Jove R. The STATs of cancer--new molecular targets come of age. Nat Rev Cancer. 2004;4(2):97-105

20. Furth PA. STAT signaling in different breast cancer sub-types. Mol Cell Endocrinol. 2014;382(1):612-5.

21. Clevenger $\mathrm{CV}$. Roles and regulation of stat family transcription factors in human breast cancer. Am J Pathol. 2004;165(5):1449-60.

22. Kolla V, Lindner DJ, Xiao W, Borden EC, Kalvakolanu DV. Modulation of interferon (IFN)-inducible gene expression by retinoic acid up-regulation of STAT1 protein in IFN-unresponsive cells. J Biol Chem. 1996:271(18):10508-14.

23. Jung HH, Lee J, Kim JH, Ryu KJ, Kang SA, Park C, et al. STAT1 and Nmi are downstream targets of Ets-1 transcription factor in MCF-7 human breast cancer cell. FEBS Lett. 2005:579(18):3941-6.

24. Gooch JL, Christy B, Yee D. STAT6 mediates interleukin-4 growth inhibition in human breast cancer cells. Neoplasia. 2002:4(4):324-31.

25. Cataldo L, Chen NY, Yuan Q, Li W, Ramamoorthy P, Wagner TE, et al. Inhibition of oncogene STAT3 phosphorylation by a prolactin antagonist, hPRL-G129R, in T-47D human breast cancer cells. Int J Oncol. 2000;17(6):1179-85.

26. Behera R, Kumar V, Lohite K, Karnik S, Kundu GC. Activation of JAK2/STAT3 signaling by osteopontin promotes tumor growth in human breast cancer cells. Carcinogenesis. 2010;31(2):192-200.

27. Bharadwaj U, Eckols TK, Kolosov M, Kasembeli MM, Adam A, Torres D, et al. Drug-repositioning screening identified piperlongumine as a direct STAT3 inhibitor with potent activity against breast cancer. Oncogene. 2014;31:0.

28. Wei $M$, He $Q$, Yang Z, Wang Z, Zhang Q, Liu B, et al. Integrity of the LXXLL motif in Stat6 is required for the inhibition of breast cancer cell growth and enhancement of differentiation in the context of progesterone. BMC Cancer. 2014;14(1):10.

29. Elkhalifa D, Alali F, Al Moustafa AE, Khalil A. Targeting triple negative breast Cancer heterogeneity with Chalcones: a molecular insight. J Drug Target. 2018;24(6):1-25.

30. West M, Blanchette $C$, Dressman H, Huang E, Ishida S, Spang $R$, et al. Predicting the clinical status of human breast cancer by using gene expression profiles. Proc Natl Acad Sci U S A. 2001;98(20):11462-7.

31. Ding L, Yan J, Zhu J, Zhong H, Lu Q, Wang Z, et al. Ligand-independent activation of estrogen receptor alpha by XBP-1. Nucleic Acids Res. 2003; 31(18):5266-74.

32. Katzenellenbogen BS. Estrogen receptors: bioactivities and interactions with cell signaling pathways. Biol Reprod. 1996;54(2):287-93. 
33. Ding LH, Ye QN, Yan JH, Zhu JH, Lu QJ, Wang ZH, et al. XBP-1 interacts with estrogen receptor alpha (ERalpha). Chin J Biotechnol. 2004;20(3):332-6.

34. Fang Y, Yan J, Ding L, Liu Y, Zhu J, Huang C, et al. XBP-1 increases ERalpha transcriptional activity through regulation of large-scale chromatin unfolding. Biochem Biophys Res Commun. 2004;323(1):269-74.

35. Katzenellenbogen BS, Montano MM, Ekena K, Herman ME, EM MI, William L. McGuire memorial lecture. Antiestrogens: mechanisms of action and resistance in breast cancer. Breast Cancer Res Treat. 1997;44(1):23-38.

36. Fujimoto $T$, Onda M, Nagai H, Nagahata T, Ogawa K, Emi M. Upregulation and overexpression of human X-box binding protein 1 (hXBP-1) gene in primary breast cancers. Breast Cancer. 2003;10(4):301-6.

37. Zhou F, Yang Y, Xing D. BCl-2 and BCl-XL play important roles in the crosstalk between autophagy and apoptosis. FEBS J. 2011;278(3):403-13.

38. Kimura I, Nakayama Y, Konishi M, Kobayashi T, Mori M, Ito M, et al. Neuferricin, a novel extracellular heme-binding protein, promotes neurogenesis. J Neurochem. 2010;112(5):1156-67.

39. Bruce A, Rybak AP. CYB5D2 requires heme-binding to regulate HeLa cell growth and confer survival from chemotherapeutic agents. PLoS One. 2014; 9(1):e86435.

40. Issa JP. Cancer prevention: epigenetics steps up to the plate. Cancer Prev Res. 2008;1 (4):219-22.

41. Feil R, Fraga MF. Epigenetics and the environment: emerging patterns and implications. Nat Rev Genet. 2011;13(2):97-109.

42. Mon AM, MacKinnon AC, Traktman P. Overexpression of the VRK1 kinase, which is associated with breast cancer, induces a mesenchymal to epithelial transition in mammary epithelial cells. PLoS One. 2018;13(9) PubMed PMID: WOS:000444222400040. English.

43. Salzano M, Vazquez-Cedeira M, Sanz-Garcia M, Valbuena A, Blanco S, Fernandez IF, et al. Vaccinia-related kinase 1 (VRK1) confers resistance to DNA-damaging agents in human breast cancer by affecting DNA damage response. Oncotarget. 2014;5(7):1770-8.

44. Whelan G, Kreidl E, Wutz G, Egner A, Peters JM, Eichele G. Cohesin acetyltransferase $\mathrm{EscO} 2$ is a cell viability factor and is required for cohesion in pericentric heterochromatin. EMBO J. 2012;31(1):71-82.

45. Evans EB, Hogarth C, Evanoff RM, Mitchell D, Small C, Griswold MD. Localization and regulation of murine Esco2 during male and female meiosis. Biol Reprod. 2012;87(3):61.

46. Bender D, Da Silva EML, Chen JR, Poss A, Gawey L, Rulon Z, et al. Multivalent interaction of ESCO2 with the replication machinery is required for sister chromatid cohesion in vertebrates. Proc Natl Acad Sci U S A. 2020; 117(2):1081-9 PubMed PMID: WOS:000508976200045. English.

47. Kim BC, Han NK, Byun HO, Kim SS, Ahn EK, Chu IS, et al. Time-dependently expressed markers and the characterization for premature senescence induced by ionizing radiation in MCF7. Oncol Rep. 2010;24(2):395-403.

48. Smyth GK Limma: linear models for microarray data. Bioinformatics and computational biology solutions using R and Bioconductor. Berlin: Springer; 2005. p. 397-420.

49. Yekutieli D, Benjamini Y. Resampling-based false discovery rate controlling multiple test procedures for correlated test statistics. J Stat Plan Inference. 1999;82(1):171-96

50. Langfelder P, Horvath S. Fast R functions for robust correlations and hierarchical clustering. J Stat Softw. 2012;46(11):i11.

51. Mukherjee S, Chen Z, Gangopadhyay A. A privacy-preserving technique for Euclidean distance-based mining algorithms using Fourier-related transforms. VLDB J. 2006;15(4):293-315.

52. Wingender E. The TRANSFAC project as an example of framework technology that supports the analysis of genomic regulation. Brief Bioinform. 2008 Jul; 9(4):326-32.

53. Meyer LR, Zweig AS, Hinrichs AS, Karolchik D, Kuhn RM, Wong M, et al. The UCSC genome browser database: extensions and updates 2013. Nucleic Acids Res. 2013:41(Database issue):D64-9.

54. Shannon P, Markiel A, Ozier O, Baliga NS, Wang JT, Ramage D, et al. Cytoscape: a software environment for integrated models of biomolecular interaction networks. Genome Res. 2003;13(11):2498-504 eng.

\section{Publisher's Note}

Springer Nature remains neutral with regard to jurisdictional claims in published maps and institutional affiliations.

\section{Ready to submit your research? Choose BMC and benefit from:}

- fast, convenient online submission

- thorough peer review by experienced researchers in your field

- rapid publication on acceptance

- support for research data, including large and complex data types

- gold Open Access which fosters wider collaboration and increased citations

- maximum visibility for your research: over $100 \mathrm{M}$ website views per year

At BMC, research is always in progress.

Learn more biomedcentral.com/submissions 